\title{
Post cesarean uterocutaneous fistula with successful repair and successful outcome: A case report.
}

\author{
George Uchenna Eleje ${ }^{1,2}$, Gerald Okanandu Udigwe ${ }^{1,2}$, Mbanefo Paul Okeke ${ }^{2}$, James Maduka \\ Nwokoro $^{2}$, Lambert Chukwu Onyejiaku², Chinedu James Ezugwu ${ }^{2}$, Onyeka Kodilinye Ibeabuchi ${ }^{2}$, \\ Chinelo Ifenyinwa George ${ }^{3}$ \\ ${ }^{1}$ Effective Care Research Unit, Department of Obstetrics and Gynecology, Faculty of Medicine, Nnamdi \\ Azikiwe University, Nnewi Campus, Nigeria \\ ${ }^{2}$ Department of Obstetrics and Gynecology, Nnamdi Azikiwe University Teaching Hospital, Nnewi, Nigeria \\ ${ }^{3}$ Department of Family Medicine, Nnamdi Azikiwe University Teaching Hospital, Nnewi, Nigeria
}

\begin{abstract}
Uterocutaneous fistula is a very rare complication of cesarean section. To the best of the knowledge of the researchers, this is second of such a case previously been reported in the researchers' environment. A 23-year-old Nigerian (black African) unmarried woman presented four years after cesarean section in a local hospital with one-year history of painful and bloody discharge during menstruation from a previous Pfannenstiel scar. A fistulous tract leading from the incision scar to the uterus was diagnosed. The lesion extended to the lower uterine segment, connecting the endometrial cavity with the skin. The fistulous tract was excised followed by repair of the uterine wound and she had complete relief from symptoms. This case report highlights the rare possibility of uterocutaneous fistula occurring in a woman following cesarean section. Appropriate surgical skills and post-operative care are necessary to prevent this outcome that may be agonizing for the patient.
\end{abstract}

Keywords: Uterocutaneous fistula, Cesarean section, Uterus, Post-operative.

Accepted on May 29, 2018

\section{Introduction}

A fistula may be defined as an abnormal communication between two epithelium-lined surfaces [1]. Most uterine fistulae are between the uterus and the bowel or bladder (uterocolonic or uterovesical) due to postoperative injuries or infectious conditions [2]. An uterocutaneous fistula (communication between uterus and skin) is a rare condition, and there are only a few reports in this regard in the existing literature of its occurrence following cesarean section. Previous reports following cesarean section are associated with red degeneration of intramural fibroids, B-lynch sutures or multiple surgeries or insertion of drains or multi-associations [1,3-6]. It has also been reported following criminal abortion [7]. Because of the rarity of uterocutaneous fistula, there is no available evidence-based treatment modality [8]. We report a very rare case of post cesarean uterocutaneous fistula that was successfully treated with excision of the fistulous tract from the skin and repair of the fistulous uterus.

\section{Case Presentation}

A 23-year-old Nigerian (black African) unmarried woman presented on 27th February 2018, which was four years after cesarean section in a local hospital with one-year history of painful bloody discharge during menstruation from a previous Pfannenstiel scar. She had emergency lower segment cesarean section 4 years prior to presentation due to prolonged obstructed labor with the delivery of a male stillbirth with birth weight of $4 \mathrm{~kg}$. One week after, the cesarean section was complicated with abdominal wound breakdown. Three years afterward, she developed an abdominal wall mass around the incision. In addition, she had pain and menstrual discharge at abdominal surgical scar. One year after onset of symptoms, she consulted at a local health center where she was given medical treatment with antibiotics and analgesics. However, persistence of her symptoms prompted a second consultation and referral to our hospital on 29th January 2018.

In the past, she had one complicated cesarean delivery as already described otherwise there was no history of other prior abdomin-pelvic surgery. She attained menarche at 15 years and had four days duration of menstrual flow in a regular 27-day cycle. She had prior history of primary dysmenorrhea, but no history of dyspareunia, dysuria, or abnormal vaginal discharge. She was human immunodeficiency virus negative, had a single partner and had no history of sexually transmittable infections. She had no prior history or diagnosis of endometriosis.

On physical examination, she was afebrile, not pale, had stable vital signs and a body mass index of $24.9 \mathrm{~kg} / \mathrm{m}^{2}$ (weight 60 $\mathrm{kg}$ ). A physical examination of her abdomen showed a localized tenderness at the abdominal scar with underlying fixed mass and the speculum vaginal examination was normal. Ultrasound, full blood count, urinalysis, hepatitis B surface antigen and Hepatitis $\mathrm{C}$ antibodies were normal. On the hysterosalpingography (HSG), the preliminary film revealed a soft tissue opacification within the pelvis, but the visualized 
Citation: Eleje GU, Udigwe GU, Okeke MP, et al. Post cesarean uterocutaneous fistula with successful repair and successful outcome: A case report. J Preg Neonatal Med 2018;2(2):27-30.

bone and joint spaces were normal. However, the HSG contrast film (following injection of dilute urograffin via the uterine canula) revealed the uterine cavity to be opacified and the cervical canal had smooth outline, otherwise, the uterine cavity was normal in shape and outline. There were multiple rounded filling defects within the cervical and uterine cavity which changes shape and position with serial film consistent with air bubble. Both fallopian tubes were opacified down to the infundibula with free intra peritoneal spillage of contrast bilaterally. On lateral view, the $\mathrm{HSG}$ revealed irregular extension of contrast into the soft tissue in the lower anterior abdominal wall, however, no definite tract from the uterus was seen. The HSG findings concluded with bilateral patent uterine tube and irregular contrast extension into the soft tissue of the lower anterior abdominal wall. The intravenous urography revealed normal findings. We made a diagnosis of uterocuteneous fistula (based on the clinical and HSG findings) and our patient was counseled and booked for laparotomy for excision of the fistulous tract and repair of the fistulous uterus on 4th April 2018.

Intraoperatively, the findings revealed dense peritoneal adhesions, thickened fibrous band of the rectus sheath, anterior wall of uterus adherent to the fibrous band on to the anterior abdominal wall, normal tubes and ovaries (Figure 1). The estimated blood loss was $200 \mathrm{~mL}$. The immediate postoperative conditions were satisfactory. Histology of the biopsied lesion at the skin and anterior abdominal wall revealed normal tissue with no evidence of endometriosis. She was followed up post-surgery and she had menstruation on 29th April 2018 without the menstrual discharge at the well healed abdominal scar (Figure 2). At follow-up, the patient was also satisfied with the repair and healing because the abdominal mass had resolved as she no longer feel it.

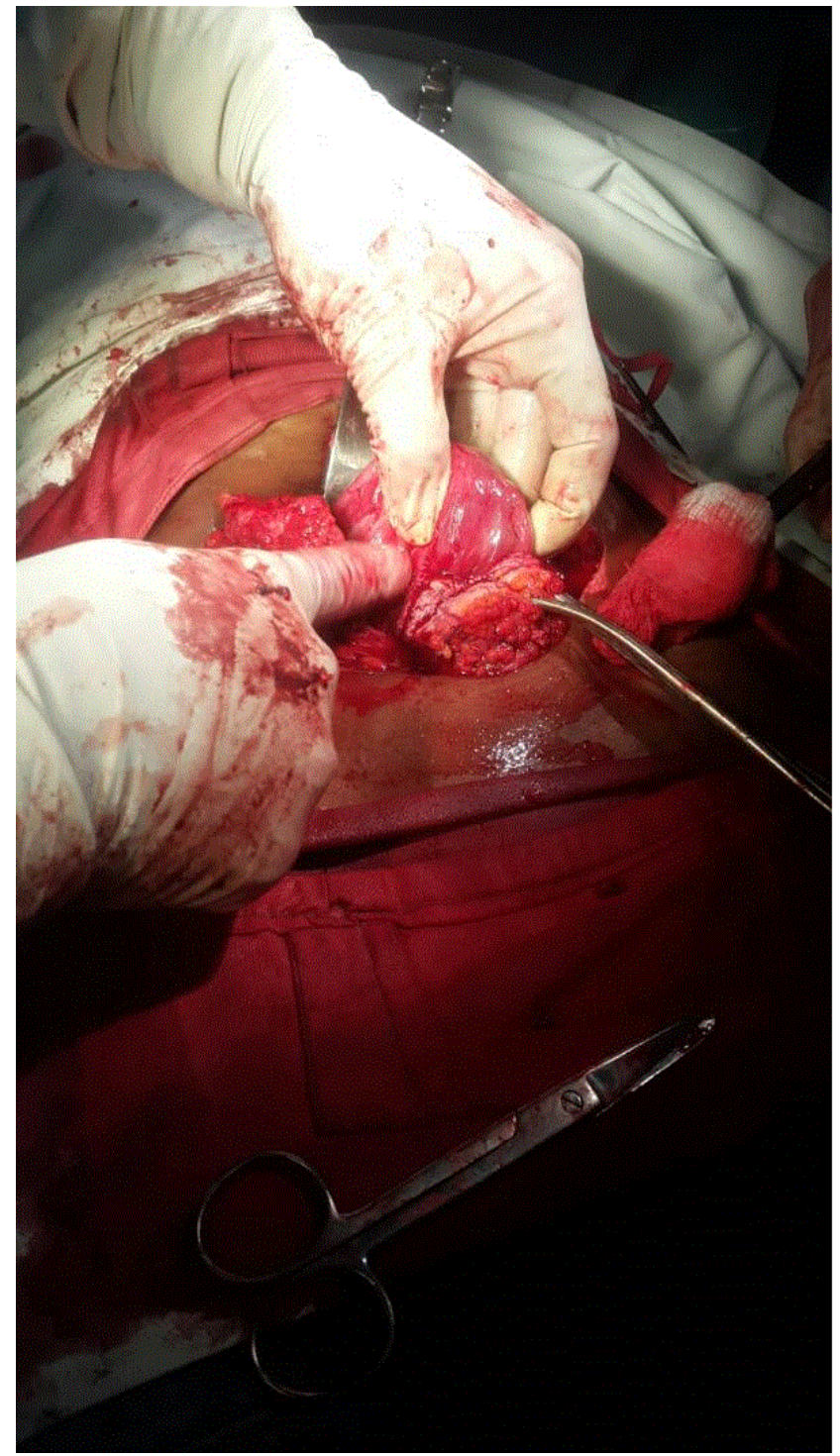

Figure 1. Fistula tract from the skin to the uterus. 


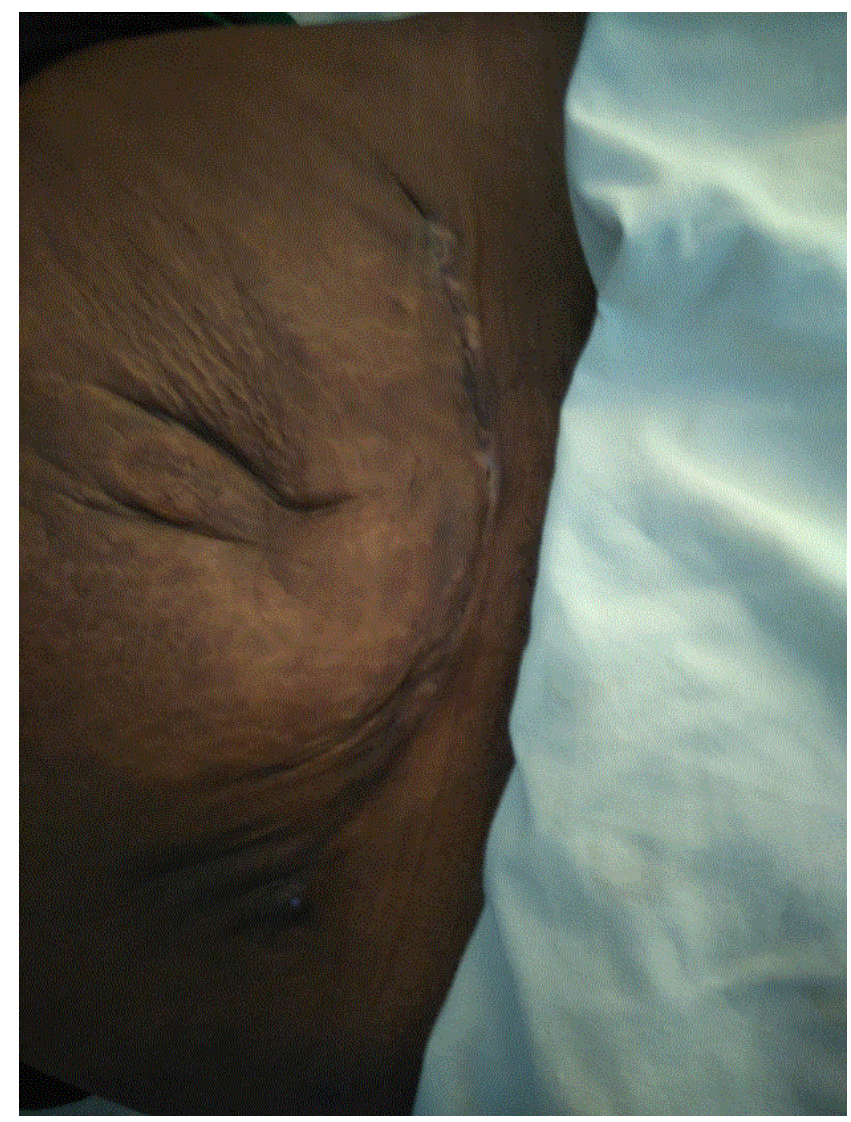

Figure 2. The healing of the pfannenstiel scar post repair.

\section{Discussion}

Most of the reported cases of uterocutaneous fistula were found following surgical intervention such as cesarean delivery or treatment for miscarriages. Thakur et al. reported a 30-yearold lady, who developed uterocutaneous fistula after undergoing emergency lower segment caesarean section for failed induction 2 months back, and developed a massive primary postpartum hemorrhage at the time of cesarean section which was managed with B-Lynch suture and vessel ligation and Limp et al. reported a 33 year-old lady who had an emergency cesarean section for retained second twin which was complicated by utero-cutaneous fistula due to red degeneration of intramural fibroids $[1,3]$. In one recent case series by Rezaei et al. there was co-existence of uterocutaneous fistula and vesico-cutaneous fistula ("twin fistula") in a multiparous lady with two previous cesarean sections [9]. In our case, we believed that the possible mechanism leading to formation of uterocutaneous fistula is due to direct contact of the uterus with the thin abdominal wall secondary to abdominal wound infection during the postpartum period.

The history of secondary wound closure in the theater during the puerperium strongly suggested post-operative wound breakdown in this patient. Poor surgical skills, anemia and inappropriate postoperative care of the wound could be the reason for the wound break down. Secondary infection might have occurred, which eroded toward the Pfannenstiel scar as well as the endometrial cavity leaving an uterocutaneous fistula. Our patient had this risk factor.

The passage of bloody discharge during menstruation from a previous Pfannenstiel scar was strongly suggestive of an uterocutaneous fistula, although cutaneous endometriotic spot may present in the same way. However, our patient did not have prior history of endometriosis.

Diagnosis of this abnormality frequently requires radiological assessments using fluoroscopic or cross-sectional modalities [10]. Fistulography is the first choice because it provides the direct means of visualizing the cutaneous fistula [11]. Other appropriate investigations include intravenous urography and pyelography or ureterography or even magnetic resonance imaging [2]. In our case, a lateral view of the HSG revealed irregular extension of contrast into the soft tissue in the lower anterior abdominal wall, although, no definite tract from the uterus was seen. Also, the intravenous urography revealed normal findings, although we could not do magnetic resonance imaging because the lateral view of the HSG was able to reveal an irregular extension of contrast into the soft tissue in the lower anterior abdominal wall.

Although there is no evidence-based treatment modality currently available for utero-cutaneous fistula, various treatment options had been reported in the management of utero-cutaneous fistula although surgery has remained the treatment of choice for endometriotic fistulae. In a previous case report of endometriotic utero-cutaneous fistula following cesarean section, Dragoumis et al. carried out a total abdominal hysterectomy in a 44-year-old lady [12]. However, in another prior case report of uterocutaneous fistula following term abdominal pregnancy, Promsonthi and Herabutya performed a subtotal hysterectomy [13]. Similar to Shukla et al. [14] case report, in our case, a more conservative surgical approach was observed where we had excision of the fistulous tract and repair of the fistulous uterus. However, Seyhan et al. had previously described a non-surgical method involving the use of gonadotropin-releasing hormone agonist (GnRHa) [15]. GnRHa works by suppressing menstruation and rendering the endometrial-like lining of the fistulous tract atrophic, with resultant spontaneous closure of the fistula. In our case, we could not resort to medical treatment because; the patient chose surgical option so as to resolve the abdominal mass caused by the fibrosed rectus sheath. Additionally, the medical treatment is not only readily available, but they are expensive. Despite these, more studies are required to inform evidence-based treatment including the mechanisms of formation of fistula following cesarean section.

\section{Conclusions}

This case report highlights the very rare possibility of uterocutaneous fistula occurring in a woman following cesarean section. Appropriate surgical skills and postoperative care are necessary to prevent an outcome that may be agonizing for the patient. While there is no evidence-based modality of therapy, further researches are necessary to 
Citation: Eleje GU, Udigwe GU, Okeke MP, et al. Post cesarean uterocutaneous fistula with successful repair and successful outcome: A case report. J Preg Neonatal Med 2018;2(2):27-30.

explicate the mechanisms of this fistula following cesarean section. Imaging studies are instrumental in these evaluations.

\section{Authors' Contributions}

GOU and GUE, managed the patient, conceived the manuscript, and did review of literature. GUE and MPO performed the surgery. MPO, JMN, LCO, CJE, OKI and CIG did review of literature and provided critical revision to the manuscript. All authors read and approved the final copy of the manuscript.

\section{Ethics Approval and Consent to Participate}

Informed consent was obtained from the patient.

\section{Consent for Publication}

Written informed consent was obtained from the patient for publication of this case report and any accompanying images. A copy of the written consent is available for review by the Editor-in-Chief of this journal.

\section{Competing Interests}

The authors declare that they have no competing interests.

\section{References}

1. Thakur M, Rathore SS, Jindal A, et al. Uterocutaneous fistula following B-Lynch suture for primary postpartum haemorrhage. BMJ Case Rep. 2018.

2. Eldem G, Turkbey B, Balas S, et al. MDCT diagnosis of uterocutaneous fistula. Eur J Radiol. 2008;67:129-3.

3. Lim PS, Shafiee MN, Ahmad S, et al. Utero-cutaneous fistula after caesarean section secondary to red degeneration of intramural fibroid. Sex Reprod Healthc. 2012;3:95-6.

4. Vellanki VS, Gogineni S, Kanakamedala JS. Case Report of Uterocutaneous Fistula. J Women's Health Care. 2015;4:231.

5. Maddah G, Fattahi AS, Rahnama A, et al. Uterocutaneous Fistula Following Cesarean Section: Successful Management of a Case. Iran J Med Sci. 2016;41:157-60.
6. Rezaei Z, Shahraki Z, Shirazi M. Utero-Cutaneous Fistula as a Rare Complication After Cesarean Delivery: Case Series. J Obstet Gynecol Cancer Res. 2017;2:e14071.

7. Okoro O, Onwere S. Retained products of conception in a utero cutaneous fistula: a case report. Niger J Clin Pract. 2008;11:170-1.

8. Thubert T, Denoiseux C, Faivre E, et al. Combined conservative surgical and medical treatment of a uterocutaneous fistula. J Minim Invasive Gynecol. 2012;19:244-7.

9. Rezaei Z, Shahraki Z, Shirazi M. Utero-cutaneous Fistula as a rare complication after cesarean delivery: case series. J Obstet Gynecol Cancer Res. 2017;2:e14071.

10. Pant PR. Utero-cuteneous fistula: Rare complication of caesarean section. Nepal J Obstet Gynaecol. 2012;7:66-7.

11. Promsonthi P, Herabutya Y. Uterocutaneous fistula in term abdominal pregnancy. Eur J Obstet Gynecol Reprod Biol. 2007;132:239-41.

12. Dragoumis K, Mikos T, Zafrakas M, et al. Endometriotic uterocutaneous fistula after cesarean section. A case report. Gynecol Obstet Invest. 2004;57:90-2.

13. Promsonthi P, Herabutya Y. Uterocutaneous fistula in term abdominal pregnancy. Eur J Obstet Gynecol Reprod Bio. 2007;132:237-44.

14. Shukla D, Pandey S, Pandey LK, et al. Repair of uterocutaneous fistula. Obstet Gynecol. 2006;108:732-3.

15. Seyhan A, Ata B, Sidal B, et al. Medical treatment of uterocutaneous fistula with gonadotropin-releasing hormone agonist administration. Obstet Gynecol. 2008;111:526-8.

\section{*Correspondence to}

\author{
George Uchenna Eleje \\ Department of Obstetrics and Gynecology \\ Nnamdi Azikiwe University \\ Nigeria \\ E-mail: gu.eleje@unizik.edu.ng
}

